\title{
Intron mobility in phage T4 occurs in the context of recombination-dependent DNA replication by way of multiple pathways
}

\author{
John E. Mueller, Jonathan Clyman, Yi-Jiun Huang, Monica M. Parker, and Marlene Belfort ${ }^{1}$ \\ Molecular Genetics Program, Wadsworth Center, New York State Department of Health, and School of Public Health, \\ State University of New York at Albany, Albany, New York 12201-2002 USA
}

\begin{abstract}
Numerous group I introns in both prokaryotes and eukaryotes behave as mobile genetic elements. The functional requirements for intron mobility were determined in the $\mathrm{T} 4$ phage system using an in vivo assay to measure intron homing with wild-type and mutant derivatives. Thus, it was demonstrated that intron mobility occurs in the context of phage recombination-dependent replication, a pathway that uses overlapping subsets of replication and recombination functions. The functional requirements for intron homing and the nature of recombinant products are only partially consistent with the accepted double-strand-break repair (DSBR) model for intron inheritance, and implicate additional homing pathways. Whereas ambiguities in resolvase requirements and underrepresentation of crossover recombination products are difficult to rationalize strictly by DSBR, these properties are most readily consistent with a synthesis-dependent strand annealing (SDSA) pathway. These pathways share common features in the strand invasion steps, but differ in subsequent repair synthesis and resolution steps, influencing the genetic consequences of the intron transfer event.
\end{abstract}

[Key Words: Group I intron; intron homing; recombination-dependent replication; double-strand-break repair; synthesis-dependent strand annealing pathway]

Received September 29, 1995; revised version accepted December 1, 1995.

Two of the three self-splicing introns in bacteriophage T4 behave as mobile genetic elements (Quirk et al. 1989|. Mobility is manifest as a homing reaction, in which the introns are transferred efficiently to cognate intronless alleles during genetic crosses. The homing reaction requires homology of exon sequences (Quirk et al. 1989; M.M. Parker and M. Belfort, in prep.) and occurs by virtue of endonucleases encoded within the mobile introns. These endonucleases I-TevI and I-TevII, the products of the $t d$ and sunY introns, respectively, make a double-strand break (DSB) in the recipient allele (BellPedersen et al. 1990; Chu et al. 1990). The resulting DNA ends stimulate the recombination events that culminate in intron inheritance.

In the absence of phage functions homing cannot occur between plasmid-borne intron donor and recipient alleles in Escherichia coli. Therefore, initial investigations into the mechanism and requirements of homing of the $t d$ intron were undertaken using a relatively simple phage $\lambda$ model system (Clyman and Belfort 1992). Under these conditions, homing required a $5^{\prime}-3^{\prime} \lambda$ exo-

\footnotetext{
${ }^{1}$ Corresponding author.
}

nuclease and its associated annealing function, the $E$. coli $3^{\prime}-5^{\prime}$ exonuciease III, and the $E$. coli recombinase RecA. These requisite functions allow formation of single-stranded DNA tails that undergo homologous strand invasion, facilitating precise intron insertion (Clyman and Belfort 1992), and are consistent with DSB-initiated recombination (Orr-Weaver et al. 1981; Szostak et al. 1983). An adaptation of the DSB repair (DSBR) pathway as it applies to intron homing in the phage system is illustrated in Figure 1.

Although the phage $\lambda$ system provided initial insights, a more thorough analysis requires studying intron hom ing in its natural setting of $\mathrm{T} 4$ phage infection. The $\mathrm{T} 4$ infectious cycle is characterized by multiple, interwoven pathways of recombination, replication, and DNA repair (for review, see Mosig 1994). After initial origin-dependent replication, phage DNA synthesis becomes dependent on a recombination-driven mechanism in which invading DNA ends serve as primers for initiation of replication.

Numerous T4-encoded functions are required for DNA replication and variants of these functions have been categorized based on their replication phenotype (for review, see Mosig 1994). DNA zero (D0) mutants, 
Mueller et al.

Figure 1. Adaptation of the DSBR pathway to intron homing in a phage-to-plasmid model system. After a plasmid carrying the intronless recipient allele is cleaved by the intronencoded endonuclease $(A, B)$ nucleolytic degradation results in the formation of a doublestrand gap $(C)$. Strand invasion by an exposed $3^{\prime}$ end of a cleaved recipient into homologous sequences of a donor allele in the phage genome results in formation of a synaptic complex $(D)$. Repair synthesis through the intron, by the D-loop formation, produces double Holliday junction intermediates $\left(E, E^{\prime}\right)$ that are resolved to generate two intron-containing alleles $\left(F, F^{\prime}\right)$. If an even number or no crossover isomerizations take place $\langle E|$, the same strands in each junction will be cleaved by the resolving endonuclease, producing two noncrossover products $(F)$. If an odd number of crossover isomerizations occur $\left(E^{\prime}\right)$, opposite pairs of strands in the two junctions will be cleaved resulting in a single crossover product and the integration of plasmid DNA into the phage genome $\left(F^{\prime}\right)$. (Shaded bars) Intron DNA; (open bars) exon DNA; (solid line) plasmid DNA; (wavy line) phage DNA; (half arrows) 3' end of DNA strands; (arrowheads) resolvase cleavage sites.

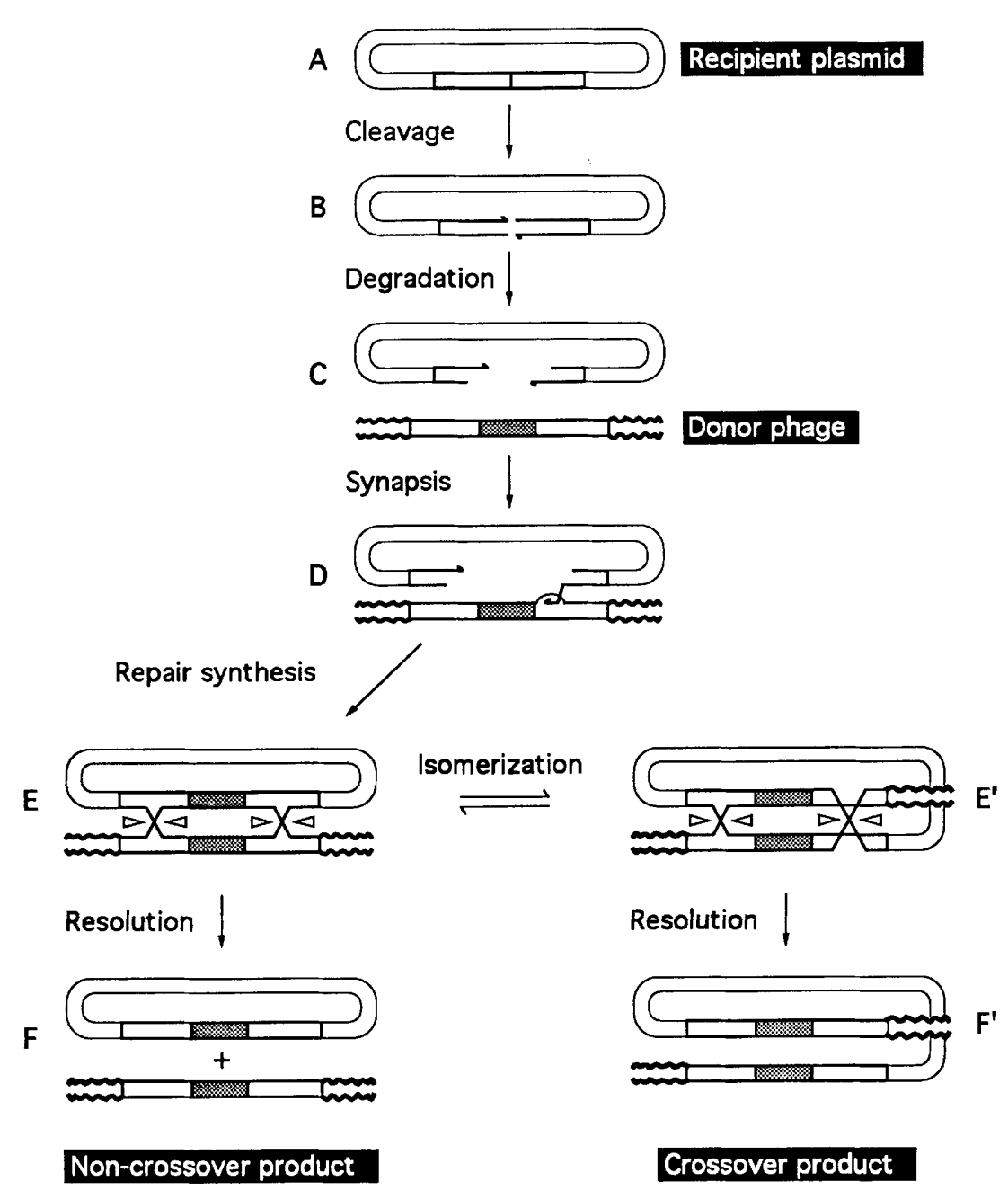

A Cleavage

(

Donor phage

Repair synthesis

$E^{\prime}$ defective in functions required for both origin-dependent and recombination-dependent replication, including polymerase (gp43) and its accessories (gp44, gp45, gp62), produce recombination intermediates, but no replicated DNA or viable phage (Epstein et al. 1964). The DNA slow mutants (DS) exhibit a markedly slow DNA synthesis phenotype, and include variants in functions that provide DNA precursors, such as dNMP kinase (gpl). The DNA delay (DD) mutants are those that exhibit a defect in early origin-dependent replication, but allow later recombination-dependent replication. This phenotype is shared by variants of topoisomerase II subunits (gp39, gp52, gp60) (Liu et al. 1979; Stetler et al. 1979) and primase (gp61), which generates RNA pentamers required for lagging strand synthesis (Nossal and Hinton 1987). Subsequently, these primers are removed from the newly synthesized strand by T4-encoded RNase $H$, which also exhibits $5^{\prime}-3^{\prime}$ DNA exonuclease activity (Hollingsworth and Nossal 1991).

Functions that are required for recombination-dependent replication include recombinase (UvsX) and its accessory (UvsY) (Yonesaki and Minagawa 1989), DNA helicase (gp41) and its accessory (gp59) (Yonesaki 1994), a putative $5^{\prime} \cdot 3^{\prime}$ exonuclease (gp46) and its accessory (gp47) (Cunningham and Berger 1977, 1978; Mickelson and Wiberg 1981), DNA ligase (gp30) (Cunningham and Berger 1977), and single-stranded DNA-binding protein (gp32) (Kodadek 1990). Mutants in these functions exhibit a DNA arrest (DA) phenotype whereby early replication proceeds, but late recombination-dependent replication is inhibited. Although mutants in the T4 function that resolves recombination intermediates (gp49) exhibit a wild-type DNA synthesis phenotype, gp49 is required for both efficient DNA packaging and phage viability (Kemper and Brown 1976; Mizuuchi et al. 1982; Mosig et al. 1991).

Endonuclease-mediated mobility of group I introns is a phylogenetically widespread process, occurring in mitochondria, chloroplasts, and nuclei of lower eukaryotes, as well as in bacteriophage (for review, see Lambowitz 1989; Perlman and Butow 1989; Lambowitz and Belfort 1993; Belfort and Perlman 1995). The well-characterized, genetically defined recombination, replication, and repair pathways in the phage/bacterial system provide an appropriate background in which to study the mechanism of intron mobility. In this paper we examine the 
role of phage T4 DNA replication and recombination functions in the homing process, thereby demonstrating that intron mobility occurs within the context of recombination-dependent replication. Although the requirement for some T4 functions is consistent with the DSBR pathway for intron homing, the ambiguous requirement for Holliday junction-resolving enzymes is not. Furthermore, an underrepresenation of crossover products suggests that the homing reaction may follow at least two overlapping pathways.

\section{Results}

An in vivo intron homing assay with phage T4intron homing parallels phage replication

To identify phage replication and recombination functions that effect intron homing, we developed an assay that allows concurrent measurement of intron homing and phage DNA replication after infection with wildtype or mutant phage (Fig. 2). In the assay, the plasmid pSUT4orit $d \Delta I n-r$, which carries the $t d$ gene with a precise deletion of the 1016-bp intron, served as intron recipient. This plasmid contains a T4 replication origin, which maintains plasmid stability during infection by recombination-deficient phage (West et al. 1986; Benson and Kreuzer 1992; Clyman and Belfort 1992). Cells harboring pSUT4oritd $\Delta$ In-r were infected with either wild- type phage or phage lacking specific replication or recombination functions. Intron inheritance by the plasmid as well as phage replication were monitored by restriction hybridization analysis of total DNA from each infection. T4K10 (Selick et al. 1988), which is deficient in nucleases DenA and DenB and does not degrade plasmid DNA, was used as the intron donor, unless otherwise indicated.

A typical homing assay with wild-type $\mathrm{T} 4 \mathrm{~K} 10$ is illustrated in Figure 2. Total DNA from infected cells was isolated at various times, restricted with SspI, which cleaves T4 DNA containing hydroxymethyl cytosine, separated through agarose gels, and probed with a $t d$ exon I-specific fragment. The enzyme and probe were selected such that the recipient, donor, and recombinant homing product yield discrete fragments of distinguishable size (Fig. 2A). Southern analysis indicated that synthesis of phage DNA, represented by the $1.9-\mathrm{kb}$ band, begins within the first $5 \mathrm{~min}$ of infection and continues through $30 \mathrm{~min}$ (Fig. 2). Intron homing, monitored by the appearance of a $2.2-\mathrm{kb}$ recombinant band, begins between 10 and 15 min after infection, and then parallels phage DNA replication in highly reproducible fashion (see also WT inset in Fig. 3A). In contrast, the recipient plasmid, represented by the $1.4-\mathrm{kb}$ band, decreases through infection, reflecting both the homing event and exonucleolytic degradation. The delay in homing is con-

A

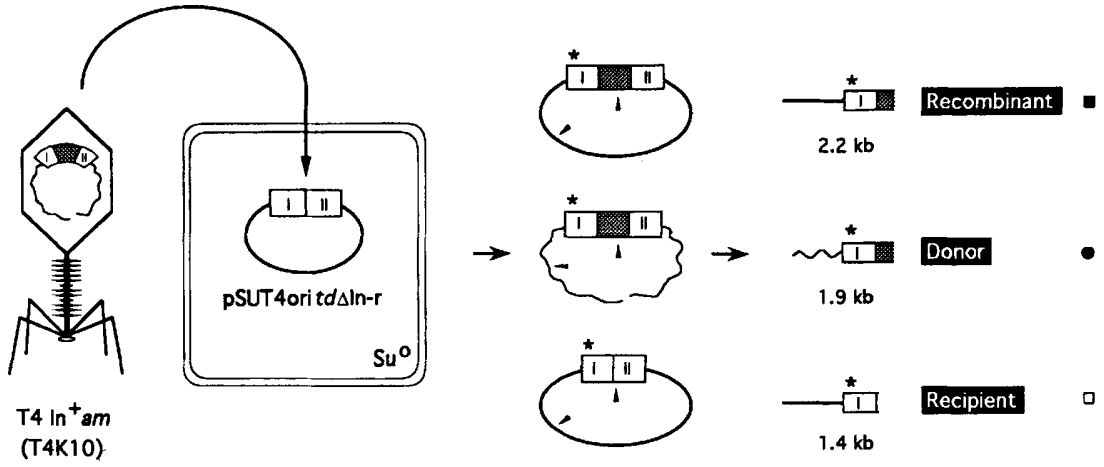

Figure 2. An in vivo assay for intron homing and phage replication. (A) Suppressor-minus $\left(\mathrm{Su}^{\circ}\right)$ host cells carrying intron recipient plasmid, pSUT4oritdsIn- $r$, were infected with intron donor $\mathrm{T} 4$ phage. (Open bars) $t d$ exon DNA; (shaded bars) $t d$ intron DNA; (solid line) plasmid DNA; (wavy line) phage DNA. The locations of relevant SspI sites (arrowheads) and the predicted sizes of fragments recognized by the $t d$ exon I-specific probe $\left({ }^{*}\right)$ are indicated for each DNA species. Symbols correspond to species in $B$ and $C$. $(B)$ Total DNA was digested with $S s p I$, electrophoresed through $1 \%$ agarose and analyzed by Southern hybridization using a $t d$ exon I-specific probe. (Lane 1) T4K10 donor (D) DNA; (lane 2) recipient (R) DNA; (lanes 3-8) DNA from T4K10-infected plasmid-containing cells at the indicated times. Sizes of relevant bands are indicated on the right. $(C)$ Gel from $B$ was quantified and the relative intensity of each band was plotted. (D) Recombinant plasmid; $(\square)$ recipient plasmid; (O) donor phage. 
Mueller et al.
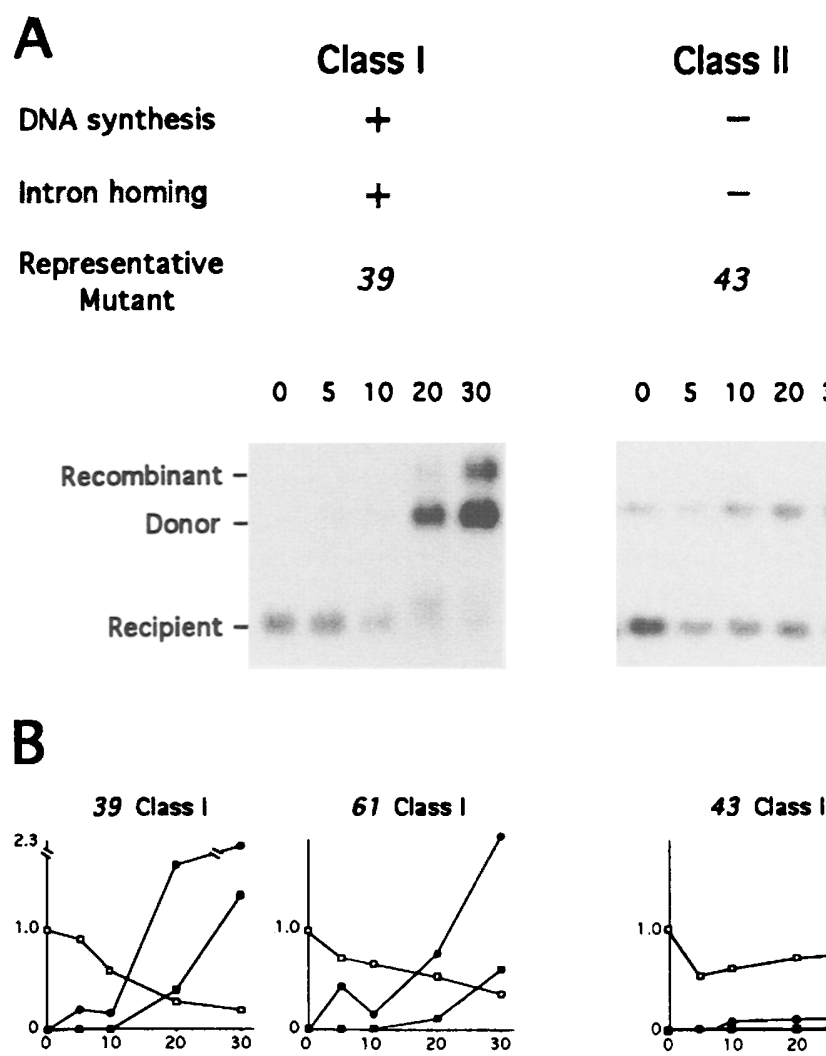

61 Class I

$0 \quad 5 \quad 102030$
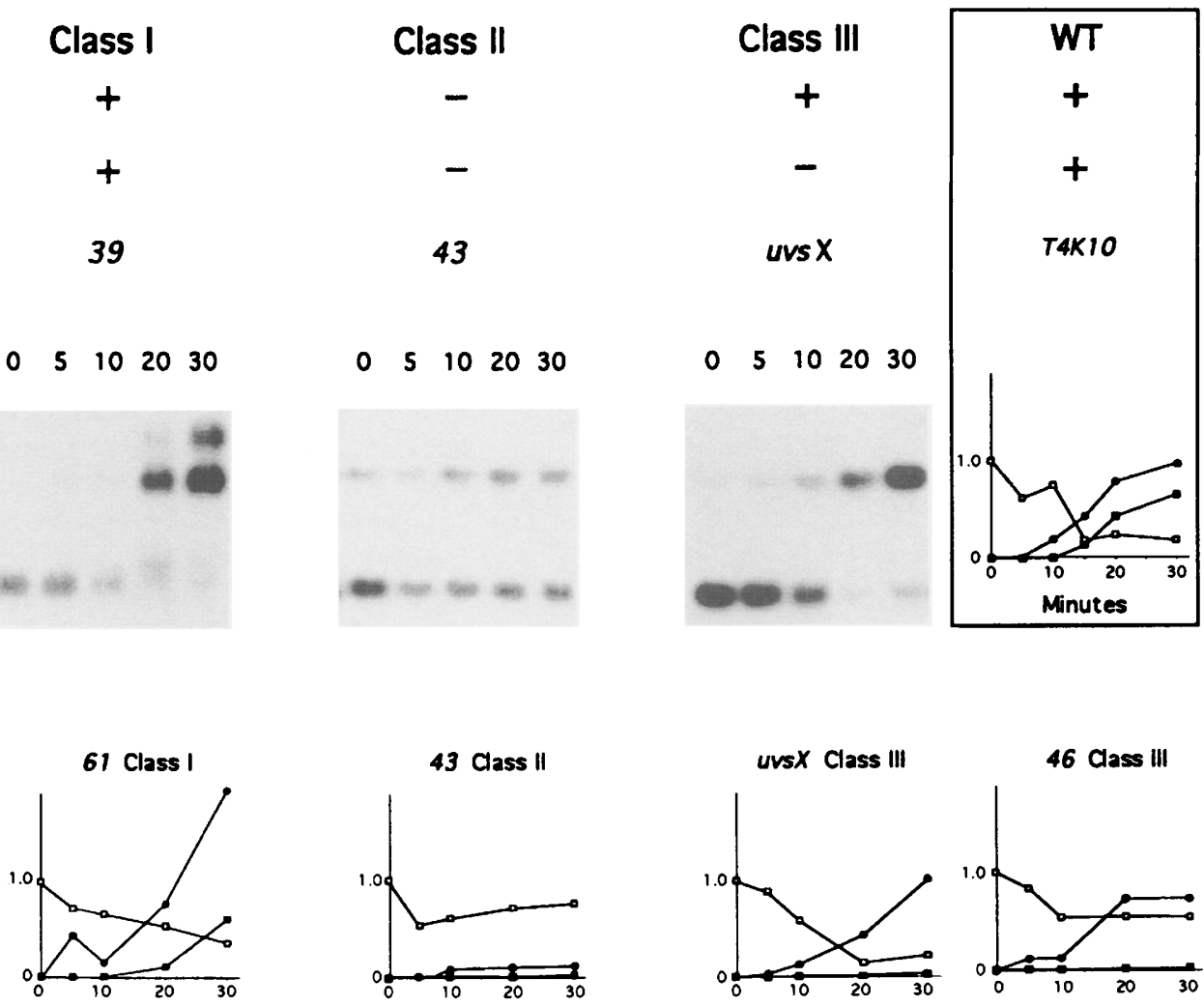

43 Class II

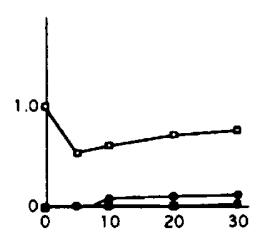

41 Class II

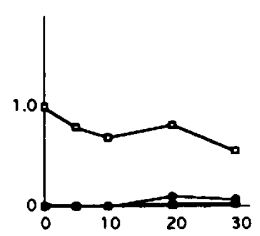

Class II

$44,45,62,1$
uvsX Class III
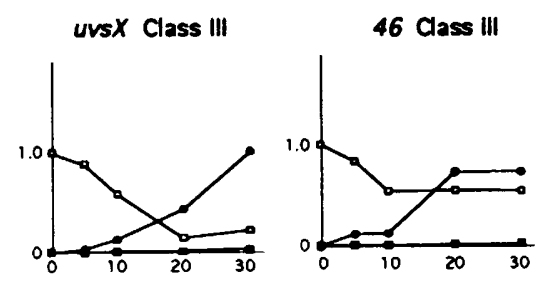

32 Class III

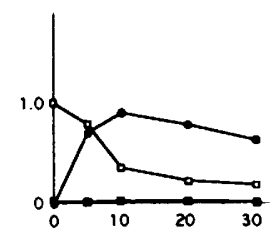

Class III

uvsY,30,47,59

Figure 3. Intron homing and phage DNA replication in the wild type and phage mutants. $|A|$ Southern analysis of representative phage T4 mutants. DNA was prepared from recipient plasmid-containing cells infected with T4K10am 39 , T4K10am43, and T4K10am-uvsX, representing the three mutant classes, for the indicated times $(0-30 \mathrm{~min})$. Southern blots were hybridized with a $t d$ exon I-specific probe as in Fig. 2. (B) Quantitative analysis of intron homing and DNA replication. Parental phage T4K10 (WT, inset) and T4K10 variants with mutations in the indicated genes were analyzed using a PhosphorImager. (ロ) Recombinant plasmid; ( $\square$ ) recipient plasmid; $(0)$ donor phage.

sistent with the expression of I-TevI activity at $\sim 10 \mathrm{~min}$ after infection (Gott et al. 1988; data not shown). Hybridization with a probe to the sunY (nrdD) gene, which is not linked to the $t d$ gene, served as an independent measure of phage replication. The kinetics of phage (donor) DNA synthesis mirrored that with the $t d$ probe, indicating that replication at the $t d$ locus is not affected by the homing reaction (data not shown).

Transcription of I-TevI depends on the expression of gene 55, which encodes a specificity factor necessary for recognition of late phage promoters by $E$. coli RNA poly- merase (Gott et al. 1988). When infection with a variant phage deficient in gp55 was used to assess background recombination in the absence of I-TevI activity, intron homing was undetectable (data not shown). Similarly, intron homing was not observed when a variant recipient plasmid, which is not cleavable by I-TevI, was used with wild-type T4K10 (data not shown). These results confirm the requirement for a DSB in intron inheritance, and validate the assay.

We chose a set of phage deficient in functions that represent critical components of replication and recom- 
bination pathways for a kinetic analysis of DNA synthesis and intron homing (Fig. 3; Table 1). An additional set of phage mutants in related functions was selected for analysis at a single timepoint (Table 1). In the latter assays, either T4K10 or T4D, which expresses functional nucleases DenA and DenB, served as donor. During T4D infections, some plasmid degradation was evident resulting in somewhat variable levels of recombinant product; however, for phage that were mutant in replication and recombination functions, relative ratios of intron homing to phage DNA replication were comparable to those observed during T4K10 infection (Table 1). Most phage variants of T4K10 and T4D contained an amber mutation in relevant genes (Table 1), whereas the E. coli B host strain carried a mutation in the rpsL gene, conferring streptomycin resistance and reducing translational readthrough of amber stop codons (Karam and O'Donnell 1973).

The observed phenotypes of DNA synthesis and intron homing indicated that the mutants can be separated into three classes (Fig. 3; Table 1). Class I mutants are proficient in DNA synthesis and intron homing, class II mutants are deficient in DNA synthesis and intron homing, and class III mutants allow DNA synthesis, but do not support intron homing. For those variants in which DNA synthesis occurred, classifications were based on the extent of intron homing relative to phage replication as reflected in recombinant-to-donor ratios (Table 1).

Table 1. DNA replication and intron homing phenotypes of wild-type T4 and mutants

\begin{tabular}{|c|c|c|c|c|c|c|c|c|}
\hline Class $^{\mathrm{a}}$ & Gene $^{b}$ & Protein Function $^{c}$ & $\mathrm{I}-T e v \mathrm{I}^{\mathrm{d}}$ & Replication $^{\mathrm{e}}$ & Homing $^{f}$ & $\begin{array}{l}\text { Phage } \\
\text { background }\end{array}$ & $\begin{array}{l}\text { Recombinant/ } \\
\text { donor }^{\text {h }}\end{array}$ & Range $^{i}$ \\
\hline wt & $w t$ & Wild type & $\begin{array}{c}++ \\
\text { N.T. }\end{array}$ & $\mathbf{W T}$ & $\begin{array}{l}+ \\
+\end{array}$ & $\begin{array}{l}\mathbf{K} \\
\mathbf{D}\end{array}$ & $\begin{array}{l}1.00 \\
1.00\end{array}$ & \\
\hline I & $\begin{array}{l}39 \\
52 \\
60 \\
49\end{array}$ & $\begin{array}{l}\text { Primase } \\
\text { Topoisomerase }\end{array}$ & $\begin{array}{c}+ \\
\text { N.T. } \\
++ \\
\text { N.T. } \\
\text { N.T. } \\
\text { N.T. } \\
++ \\
\text { N.T. }\end{array}$ & $\begin{array}{l}\text { DD } \\
\text { DD } \\
\text { DD } \\
\mathbf{W T}\end{array}$ & $\begin{array}{l}+ \\
+ \\
+ \\
+ \\
+ \\
+ \\
+ \\
+\end{array}$ & $\begin{array}{l}\mathbf{K} \\
\mathrm{D} \\
\mathbf{K} \\
\mathrm{D} \\
\mathrm{D} \\
\mathrm{D} \\
\mathbf{K} \\
\mathrm{D}\end{array}$ & $\begin{array}{l}0.93 \\
0.33 \\
1.23 \\
1.95 \\
1.13 \\
1.02 \\
0.52 \\
0.78\end{array}$ & $\begin{array}{c}0.43-1.23(3) \\
0.32-0.33(2) \\
0.96-1.57(3) \\
0.74-2.72(4) \\
1.13(1) \\
1.02(1) \\
0.32-0.72(2) \\
0.57-0.99(2)\end{array}$ \\
\hline II & $\begin{array}{l}43 \\
44 \\
45 \\
62 \\
41 \\
1\end{array}$ & $\begin{array}{l}\text { Helicase } \\
\text { dNMP kinase }\end{array}$ & $\begin{array}{l}- \\
\text { N.T. } \\
\text { N.T. } \\
\text { N.T. } \\
\text { N.T. } \\
\text { N.T. } \\
\text { N.T. } \\
- \\
\text { N.T. }\end{array}$ & $\begin{array}{l}\text { D0 } \\
\text { D0 } \\
\text { D0 } \\
\text { DA } \\
\text { DS }\end{array}$ & $\begin{array}{l}- \\
- \\
- \\
- \\
- \\
- \\
-\end{array}$ & $\begin{array}{l}\mathbf{K} \\
\mathrm{D} \\
\mathrm{K} \\
\mathrm{D} \\
\mathrm{K} \\
\mathrm{D} \\
\mathrm{D} \\
\mathrm{K} \\
\mathrm{D}\end{array}$ & $\begin{array}{l}\text { N.A. } \\
\text { N.A. } \\
\text { N.A } \\
\text { N.A } \\
\text { N.A } \\
\text { N.A } \\
\text { N.A } \\
\text { N.A } \\
\text { N.A }\end{array}$ & $\begin{array}{l}\text { N.A. } \\
\text { N.A. } \\
\text { N.A } \\
\text { N.A } \\
\text { N.A } \\
\text { N.A } \\
\text { N.A } \\
\text { N.A } \\
\text { N.A }\end{array}$ \\
\hline III & $\begin{array}{c}46 \\
47 \\
\text { uvsX } \\
\text { uvsY } \\
32\end{array}$ & $\begin{array}{l}\text { Putative exonuclease } \\
\text { Exonuclease acc } \\
\text { Recombinase } \\
\text { Recombinase acc } \\
\text { Ssb protein }\end{array}$ & $\begin{array}{c}+ \\
\text { N.T. } \\
\text { N.T. } \\
++ \\
\text { N.T. } \\
++ \\
\text { N.T. } \\
\text { N.T. } \\
\text { N.T. }\end{array}$ & $\begin{array}{l}\text { DA } \\
\text { DA } \\
\text { DA } \\
\text { DA }\end{array}$ & $\begin{array}{l}- \\
- \\
- \\
- \\
- \\
- \\
- \\
-\end{array}$ & $\begin{array}{l}\mathbf{K} \\
\mathrm{D} \\
\mathrm{D} \\
\mathbf{K} \\
\mathrm{K} \\
\mathbf{K} \\
\mathrm{D} \\
\mathrm{K} \\
\mathrm{D}\end{array}$ & $\begin{array}{l}\mathbf{0 . 0 1} \\
0.08 \\
0.02 \\
\mathbf{0 . 0 6} \\
0.08 \\
\mathbf{0 . 0 1} \\
0.08 \\
0.03 \\
0.05\end{array}$ & $\begin{array}{r}0-0.02(2) \\
0.03-0.12(2) \\
0-0.04(2) \\
0.05-0.06(2) \\
0.03-0.13(2) \\
0-0.03(5) \\
0.04-0.12(2) \\
0.02-0.03(2) \\
0-0.10(2)\end{array}$ \\
\hline
\end{tabular}

${ }^{a}$ Homing classes based on DNA replication and intron homing phenotypes: class I, replication-proficient, intron homing-proficient; class II, replication-defective, intron homing-defective; class III, replication-proficient, intron homing-defective.

bBoldface wild type (wt) and variants indicate phage infections for which kinetic analyses were performed (Fig. 2 and 3 ).

${ }^{\mathrm{c} R e v i e w e d ~ i n ~ K r e u z e r ~ a n d ~ M o r r i c a l ~(1994) . ~(S s b ~ p r o t e i n) ~ S i n g l e-s t r a n d e d ~ D N A-b i n i d n g ~ p r o t e i n ; ~(a c c) ~ a c c e s s o r y . ~}$

${ }^{\mathrm{d}}$ TevI cleavage activity: $(++\mid$ comparable to wild type; $|+|$ activity reduced and/or delayed relative to wild type; $1-\mid$ no cleavage activity detected; (N.T.) not tested.

eReplication phenotype from Mosig (1994). (DD) DNA delay; (D0) DNA zero; (DS) DNA slow; (DA) DNA arrest.

fIntron homing phenotype based on whether the product is $(+)$ or is not $(-)$ apparent at 30 min postinfection. Average recombinantto-donor ratios of $>0.3$ or $<0.1$ relative to the wild type (see penultimate column are designated as + or - , respectively.

${ }^{8}$ Strain background of T4 phage used in intron homing analysis. (D) T4D; (K) T4K10.

${ }^{\mathrm{h}}$ Average ratio of recombinant product to phage donor DNA at $30 \mathrm{~min}$ postinfection normalized to wild type; (N.A.) Not applicable due to lack of phage replication.

${ }^{\mathrm{i}}$ Range of recombinant-to-donor ratios for each variant. Number of trials are indicated in parentheses. 
Intron homing also parallels phage DNA replication in class I mutants

The homing phenotype of variants in which DNA synthesis is sustained differs depending on the particular function. Class I mutants, which are proficient in phage replication and intron homing, represent functions encoded by primase (gp61), topoisomerase (gp39, gp52, gp60), and resolvase (gp49) (Figs. 3 and 4; Table 1) genes. For each of the class I mutants, the extent of intron homing relative to phage DNA synthesis was comparable to that of the wild type (Table 1), and as for the parental phage, the kinetics of homing mirrored those of phage DNA replication (Figs. 2 and 3; data not shown!.

Whereas homing in the absence of primase function might have been anticipated as the cleaved recipient provides primers for repair synthesis, the independence of the process of both topoisomerase (gp39, gp52, gp60) and resolvase (gp49) was surprising in view of the need to resolve recombination intermediates (see Fig. 1). Recom- binant-to-donor ratios for the topoisomerase variants were higher than those for the wild type (Table 1). This observation is consistent with previous reports of the hyper-recombinogenic phenotype of topoisomerase mutants, possibly resulting from the accumulation of short single-stranded DNA fragments that would contribute to an increase in the overall level of homologous recombination during mutant infection (Leung et al. 1975). In addition, T4am39am 49 topoisomerase-resolvase double mutants were found to be homing proficient (Y-I. Huang and M. Belfort, unpubl.), raising the possibility that analogous host enzymes may play a role in the process. It has been demonstrated that $E$. coli gyrase can compensate for defective T4 topoisomerase (McCarthy 1979). However, cells infected with topoisomerase-deficient phage in the presence of novobiocin, an antibiotic that inhibits both host gyrase and topoisomerase IV activities, supported intron homing (data not shown), indicating that intron transfer does not require host type II topoisomerase activities. Similar results were obtained with host resolvase mutants (detailed below).

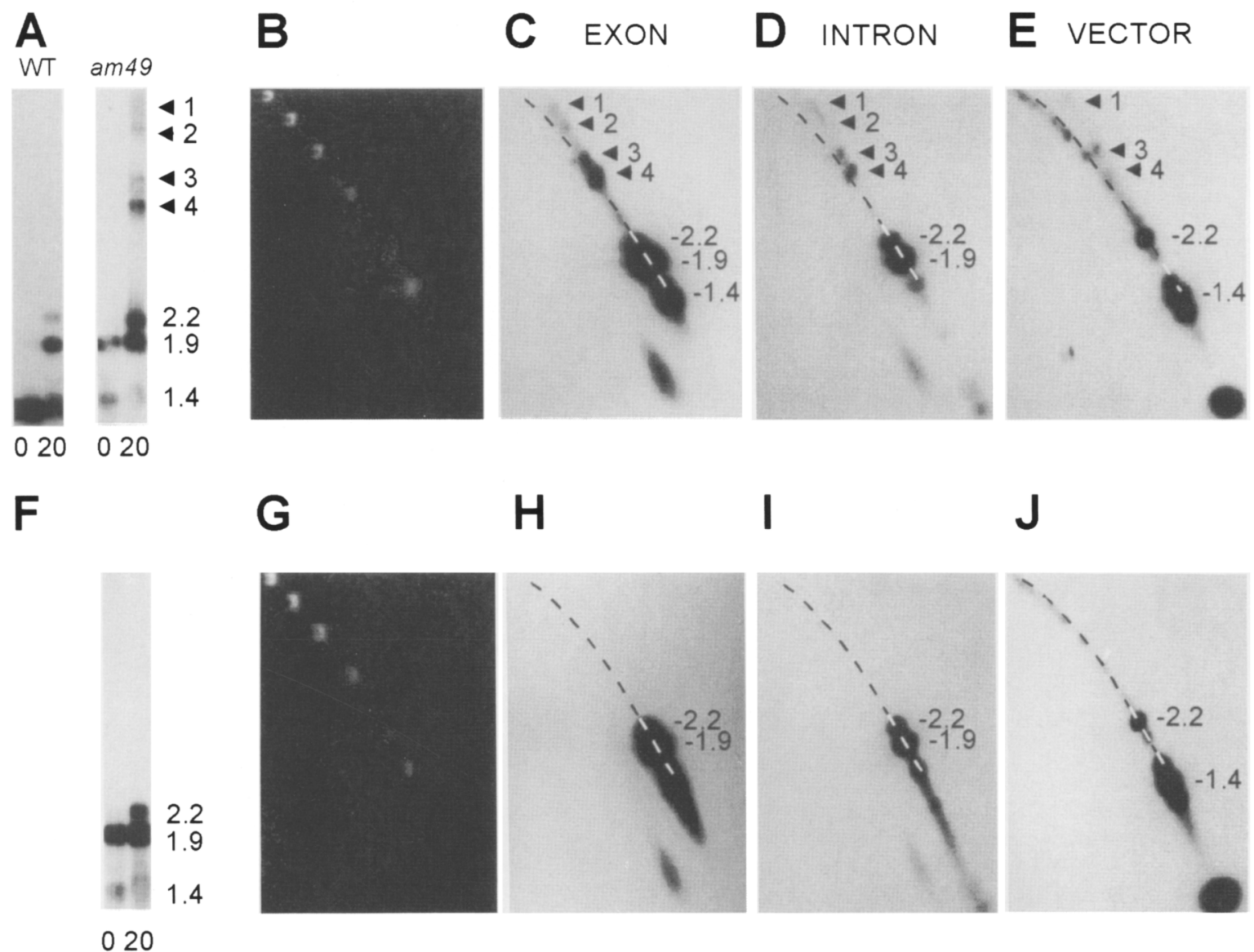

Figure 4. Analysis of DNA from T4K10am49-infected cells by two-dimensional gel electrophoresis. Recipient plasmid-containing cells were infected with T4K10am 49. Total DNA was incubated in the absence $(A-E)$ or presence $(F-I)$ of purified T4 endonuclease VII. DNA from 0 and $20 \mathrm{~min}$ after infection was separated by one-dimensional agarose gel electrophoresis, blotted and hybridized with a $t d$ exon I-specific probe $(A, F)$. DNA from a 20 -min infection was separated by two-dimensional agarose gel electrophoresis along with linear markers (1-kb ladder). Two-dimensional gels were stained with ethidium bromide $(B, G)$, blotted and hybridized with $t d$ exon $\mathrm{I}$-specific $(C, H), t d$ intron-specific $(D, I)$ and pSU8 vector-specific $(E, I)$ probes. High molecular weight bands that fall off the arc of linear markers are indicated by numbered arrowheads. 
Intron homing does not occur in replication-defective class II mutant phage

Class II mutants are deficient in DNA replication and intron homing. Variants within this class are difficult to assess in the homing assay because: (1) I-TevI activity is very low in extracts prepared from cells infected with replication-deficient phage (Table 1); this may be attributable to reduced expression because of the inhibition of late gene transcription with these phage (Christensen and Young 1983); and (2) it is not possible to determine whether the replication function is involved directly in the homing process or involved indirectly by its participation in plasmid DNA synthesis and phage viability. Bearing these caveats in mind, kinetic analyses did indicate that during infection with phage variants of DNA polymerase (gp43) and helicase (gp41), DNA synthesis was negligible and intron transfer was not observed (see Fig. 3). In addition to the 43 and 41 variants, mutants in DNA polymerase accessory functions (gp44, gp45, gp62) as well as DNA precursor synthesis (gp1) were deficient in phage replication and also failed to support intron homing at $30 \mathrm{~min}$ after infection ( $\mathrm{Ta}$ ble 1).

\section{Dependence of intron homing on specific recombination functions in class III mutants}

Mutants of the third class were proficient in DNA replication, but did not support intron homing, as typified by the uvsX mutant (see Fig. 3). I-TevI activity was detected during infection with the uvsX variant (Table 1) and loss of the recipient suggested that endonuclease cleavage and degradation of the recipient plasmid had occurred in the absence of homing (see Fig. 3). However, homing was not observed, suggesting that the UvsX recombinase is required directly. Similarly, homing was greatly reduced during infection with the uvsY variant, which encodes an accessory to the recombinase (Table 1).

Other class III variants that support phage replication but exhibit limited levels of intron homing include mutants in genes $30,32,46,47$, and 59 (Fig. 3; Table 1). Like the $u v s \mathrm{X}$ variant, kinetic analyses indicate that gene 32 and 46 mutants attained substantial levels of DNA synthesis; however, the appearance of a corresponding intron-homing recombinant product was negligible (Fig. 3; Table 1). Similarly, analyses of mutants in genes 30,47 , and 59 at 0 and $30 \mathrm{~min}$ after infection showed that phage replication occurred in these infections as well, but that no homing product was formed (Table 1). Limited intron homing upon infection with these mutants is consistent with the participation of nuclease (gp46 and gp47), single-stranded DNA-binding protein (gp32), primase-helicase accessory (gp59), and ligase (gp30) functions in recombination-dependent replication.

Although class III variants are proficient in phage replication, the possibility exists that plasmid replication may be deficient. If this were the case, intron homing events that occurred during infection with these variant phage might be obscured by the inability of the recombinant plasmid to replicate. To test this hypothesis, we subjected an $E$. coli $\mathbf{B}\left(\operatorname{str}^{\mathbf{R}}\right)$ host carrying a noncleavable recipient plasmid to infection with wild-type and variant phage. Kinetic analysis demonstrated that the extent of plasmid replication during variant infections was comparable to that of wild type (data not shown), indicating that the homing phenotype of these variants is related directly to the requirement for the function in homing, rather than plasmid replication. The exception was with the $r n h$ variant deficient in ribonuclease $\mathrm{H}$ function, where the extent of both intron homing and plasmid replication was reduced, precluding assessment of a role for this function in the mobility process.

\section{The partial requirement for T4 resolvase suggests multiple homing pathways}

The class I T4 resolvase mutant (49) supported intron homing and phage replication (Figs. 3 and $4 \mathrm{~A}$ ) with a homing efficiency, as determined by recombinant-to-donor ratios, of $\sim 50 \%$ of the parental phage (Table 1). This was the case even when these assays were performed in E. coli ruvC-recG and rus-ruvA-ruvC resolvase mutants (data not shown), where host recombination is greatly reduced ( $>500$-fold) (Lloyd 1991; Lloyd and Sharples 1993; Sharples et al. 1994). Similar results were obtained when the recombinant products were cleaved by restriction endonucleases in regions of heterology between donor and recipient on both sides of the intron (constructs illustrated in Fig. 5; data not shown). These results argue against the possibility of resolution of products by branch migration to the ends of the restricted fragments in vitro, and indicate that homing products can be formed in vivo in the absence of known resolvases.

Several high molecular mass bands, which were not observed during infections with wild type or other variant phage, appeared at 20 and $30 \mathrm{~min}$ after T4am 49 infection, concurrent with the appearance of the $2.2-\mathrm{kb}$ recombinant product (Fig. 4A). Not surprisingly, similar species were observed during T4am 49 infection in an $E$. coli ruvC-recG and rus-ruvA-ruvC background (data not shown). To determine whether these high molecular mass bands represent homing-specific recombination intermediates, we subjected the DNA to two-dimensional agarose gel electrophoresis (Bell and Byers 1983). In the first dimension, fragment separation was determined by molecular mass, whereas in the second dimension separation was based on conformation, such that linear, double-stranded DNA molecules formed a uniform arc and molecules containing disruptions of the duplex migrated away from the arc. These disruptions can include regions of single-strandedness or branching, as characteristic of recombination intermediates. Hybridization of blots with a $t d$ exon I probe revealed that exon I-specific bands (Fig. 4C, bands 1-4) ran above the arc defined by linear DNA markers (Fig. 4B). Furthermore, hybridization with a $t d$ intron-specific probe (Fig. 4D) and a recipient vectorspecific probe (Fig. 4E) revealed that three of the four 
Figure 5. Analysis of noncrossover and crossover recombinants. (A) $\mathrm{Su}^{\circ}$ host cells carrying plasmid pSUT4oritd $\Delta$ In-rPac were infected with intron donor phage T4alc7. The location of relevant PacI sites (arrowheads) and the predicted sizes of fragments recognized by the vector-specific probe $\left({ }^{*}\right)$ are indicated for each species. (Open bars) $t d$ exon DNA; (shaded bars| $t d$ intron DNA; (solid line) plasmid DNA; (wavy line) phage DNA. (B) Total DNA was digested with PacI, electrophoresed through $1 \%$ agarose and analyzed by Southern hybridization using a vector-specific probe. (Lane 1) Recipient (R) DNA; (lane 2) T4alc7 donor (D) DNA; llanes 3-10| DNA from T4alc7-infected plasmidcontaining cells at the indicated times. Sizes of relevant bands are indicated on the right. (NX) Noncrossover recombinant; (X) crossover recombinant; (R) recipient plasmid. $(C)$ Ratios of noncrossover to crossover products for indicated times from quantitation of Southern analysis depicted in $B$. Similar ratios were obtained when this experiment was performed with a 49 variant phage in a rus-ruvA-ruvC background (data not shown).
A
(D)
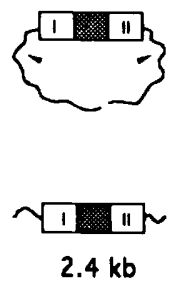

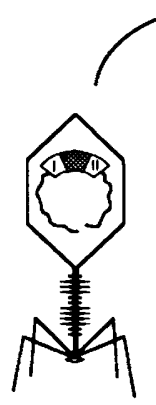

T4 alc 7 in $^{+}$

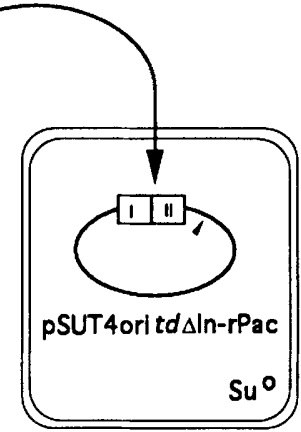

$\downarrow$
Recipient

(R)
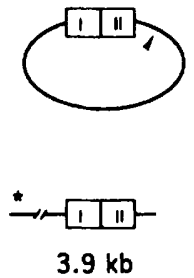

B

$\begin{array}{llllllllll}1 & 2 & 3 & 4 & 5 & 6 & 7 & 8 & 9 & 10\end{array}$

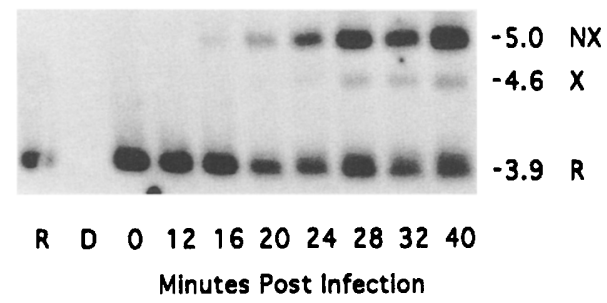

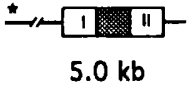

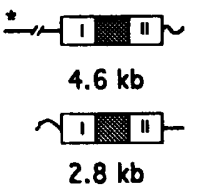

Recombinants

Non-crossover (NX)
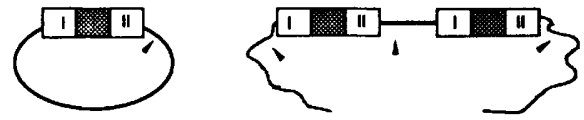

$2.8 \mathrm{~kb}$

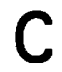

\begin{tabular}{cc} 
Min & $\frac{N X}{X}$ \\
\hline 20 & 5.5 \\
24 & 6.8 \\
28 & 5.7 \\
32 & 4.4 \\
40 & 4.6
\end{tabular}

anomalously migrating bands (bands 1, 3, and 4) contained $t d$ exon $\mathrm{I}$, $t d$ intron, and recipient plasmid DNA, indicating that these species represent homing-specific intermediates.

When similar experiments were performed with DNA that had been treated before gel electrophoresis with purified T4 endonuclease VII, the resolvase product of gene 49 , the anomalously migrating bands were not detected in either the first or second dimension (Fig. 4F, H-J). These data are intriguing because they indicate that intron homing can occur in a resolvase-limiting environment, yet homing-specific recombination intermediates are also present in a 49 mutant. Although an unknown resolvase may be present in the system and account for the observed 2.2-kb recombinant band according to the DSBR pathway, the recombinant products are consistent with the occurrence of intron homing in bacteriophage T4 by multiple pathways.

\section{Determination of crossover products among recombinants}

Another observation that is consistent with pathways other than DSBR is a bias of $\sim 4: 1$ in noncrossover-tocrossover products when assaying inheritance of plasmid by the phage (J. Clyman, Y.-J. Huang, and M. Belfort, unpubl.). Taking into account that the DSBR pathway is predicted to yield equivalent amounts of noncrossover and crossover products (Szostak et al. 1983) (see Fig. 1), this observation was of particular importance given the ambiguous requirement for known resolvases during the homing process. Because the crossover products proved 
to be unstable in phage over multiple generations, a kinetic homing assay was performed to compare noncrossover-to-crossover ratios over a single infectious cycle. This assay allowed measurement of exchanges of flanking DNA along with intron inheritance.

The recipient plasmid for this experiment was pSUT4oritd $\Delta$ In-rPac, into which a unique PacI restriction site had been engineered, such that restriction-hybridization analysis distinguished noncrossover from crossover homing products during phage infection (Fig. $5 \mathrm{~A}, \mathrm{~B} ; \mathrm{NX}$ vs. X). Although theoretically PacI cleaves modified DNA, cleaner results were obtained with phage derivative T4alc7, which is unable to modify DNA in a $\mathrm{Su}^{\circ}$ background. As shown in Figure $5 \mathrm{~B}$, a clear bias in favor of noncrossover homing products persisted throughout the course of infection. Quantitative analysis indicated that the ratio of noncrossover-to-crossover homing products was $5.4( \pm 1.0): 1$ throughout the first 40 min of infection (Fig. 5B,C). These data further implicate pathways other than conventional DSBR in the homing process.

\section{Discussion \\ Intron homing occurs in the context of recombination-dependent replication}

An in vivo assay designed to monitor intron homing relative to phage replication demonstrated that homing of the $t d$ intron in bacteriophage T4 requires overlapping subsets of replication and recombination functions. These requirements are characteristic of the recombination-dependent replication pathway (Kreuzer et al. $1988 \mathrm{~b}$ ), which is typified by homologous strand invasion of a duplex by the 3 ' end of a DNA molecule (for review, see Kreuzer and Morrical 1994; Mosig 1994|. This complex then serves as a primed substrate for DNA synthesis. Thereby, DNA ends generated by I-TevI cleavage of an intronless $t d$ allele invade a cognate, intron-containing gene, initiating a duplication event through subsequent replication.

The classification of $\mathrm{T} 4$ functions according to replication and homing phenotypes reflects the close relationship between intron mobility and recombination-dependent replication in phage T4 (Fig. 6; Table 1). Thus, intron homing occurred in DD mutants of primase (gp61) and topoisomerase (gp39, gp52, gp60), where origin-dependent replication is disrupted, but recombination-dependent replication is not. The positive replication/ homing phenotype of these variants, also common to the T4 resolvase (gp49) mutant, characterizes the class I variants in this study (Fig. 3; Table 1). With the class II mutants, D0, DS, and DA phenotypes did not support homing (Fig. 3; Table 1). Although it is not possible to distinguish a direct from an indirect role for these replication functions in homing (see Results), the lack of homing in their absence is consistent with the requirement of these functions for DNA synthesis and recombination late in infection, when intron homing takes place. These functions include DNA polymerase (gp43) and its accessories (gp44, gp45, and gp62), helicase (gp41), and enzymes providing DNA precursors (gp1). Finally, those functions implicated in late recombination-dependent replication are required for intron homing. These DA mutants include variants in putative exonucleolytic functions (gp46, gp47), recombinase activities (UvsX, UvsY), as well as single-stranded DNA-binding protein (gp32), the primase-helicase accessory function (gp59), and DNA ligase (gp30) (Fig. 3; Table 1). Their roles in the pathways for intron inheritance will be considered below (Fig. 6).

The kinetics of recombinant formation paralleled those of phage replication for wild-type $\mathrm{T} 4$ and the class I mutants that permit homing (Figs. 2 and 3). These results are in accord with a coupling of intron homing with DNA replication. The lag between the two processes is consistent with the delayed expression of I-TevI (Gott et al. 1988), which is required to make the DSB that initiates the homing process. Furthermore, the parallel replication and homing kinetics together with the dependence of homing on a DSB in the class I mutants (data not shown) argue that these experiments are measuring true DSB-mediated repair events, rather than a minor subset of events that lead to amplification of rare or spurious recombinant products. Together, these experiments argue in favor of the mobility process occurring within the context of recombination-dependent replication.

\section{Specific requirements for intron homing}

Once cleavage of the recipient by the intron-endonuclease has occurred (Fig. 6A), DNA degradation is required to ready the ends for recombination (Fig. 6B). The eccentric cleavage of I-TevI in exon I, 23 and 25 nucleotides upstream of the intron insertion site (Bell-Pedersen et al. 1990), requires both $5^{\prime} \rightarrow 3^{\prime}$ and $3^{\prime} \rightarrow 5^{\prime}$ exonuclease activities to expose exon II sequences and to generate single strands for invasion of the intron donor allele (Clyman and Belfort 1992). This nucleolytic activity is consistent with $100 \%$ coconversion of polymorphic markers between the cleavage site and the introninsertion site and with the bidirectional coconversion gradient from the intron insertion site into both exons during the homing event (Bell-Pedersen et al. 1989). The phage T4 gp46/47 complex, which may provide the nucleolytic activity either directly or by stimulating another nuclease (Mickelson and Wiberg 1981; Kreuzer et al. 1995), or RNase H, whose nucleolytic activity has been implicated in topoisomerase-DNA cleavage repair in phage T4 (D.L. Woodworth and K.N. Kreuzer, in prep.l, are candidates for contributing the required $5^{\prime} \rightarrow 3^{\prime}$ activity. Although host mutants in $3^{\prime} \rightarrow 5^{\prime} \mathrm{nu}-$ clease functions (exonuclease III, RecBC) do not inhibit homing in the T4 system (M.M. Parker and M. Belfort, unpubl.), phage nucleases, including the $3^{\prime} \rightarrow 5^{\prime} \mathrm{nu}-$ clease activity of gp 43 , remain to be tested as possible nucleolytic participants in the homing process.

A strand invasion event between the processed recipient and an intron-containing allele initiates the ensuing 


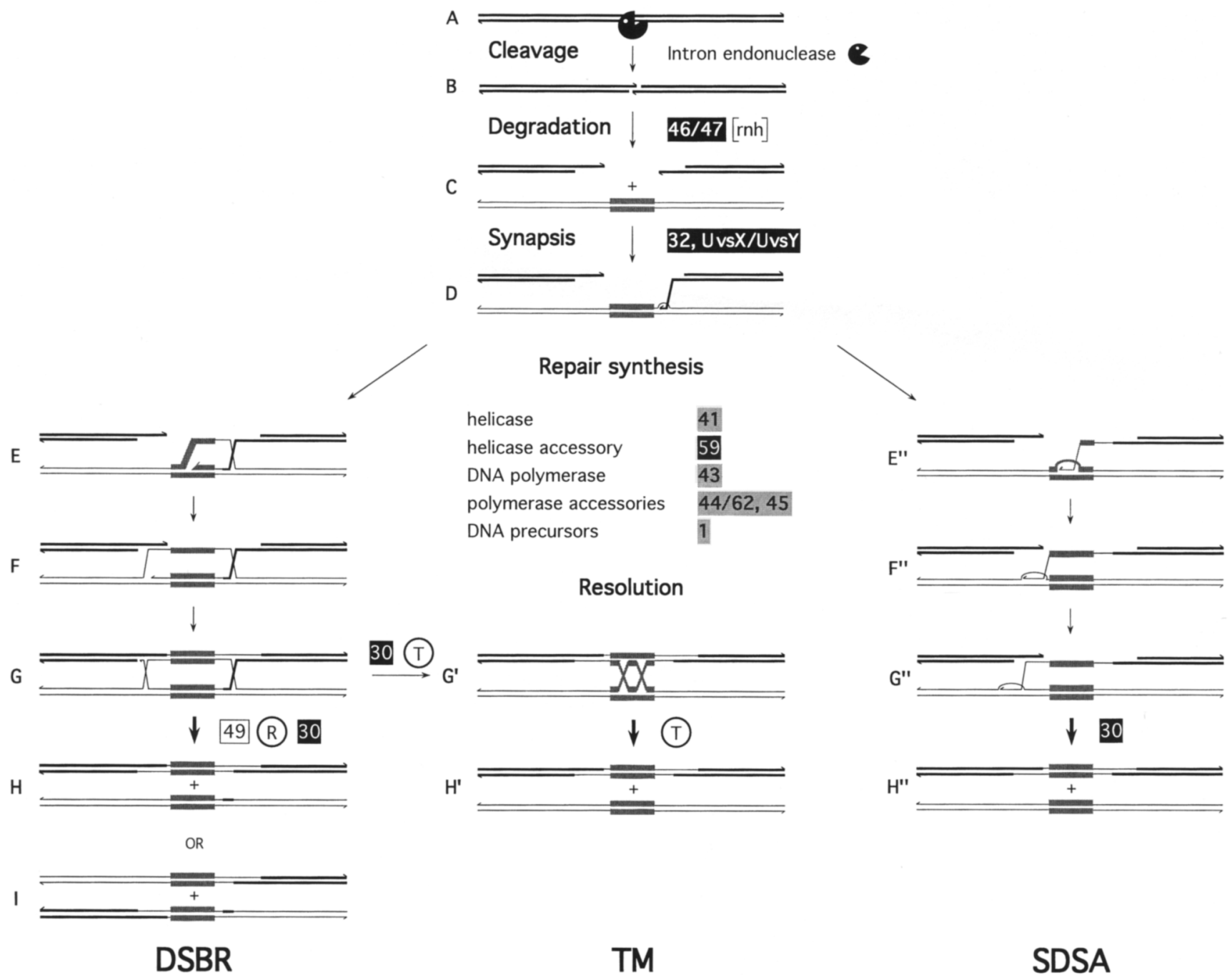

Figure 6. Alternative mechanisms for DSB-mediated intron homing. Subsequent to cleavage by the homing endonuclease $(A)$, the recipient, intronless allele (thick lines) undergoes exonucleolytic degradation and homologous sequence alignment with an introncontaining donor (thin lines) $(B, C)$. A $3^{\prime}$ end of the recipient invades the donor, which serves as a template for repair synthesis $(D)$. Cleavage of the recipient, degradation, and synapsis are common to all three pathways. In the double-strand-break repair (DSBR) pathway (left), DNA synthesis through the intron (stippled box) results in formation and expansion of a D-loop (E), which then serves as substrate for repair synthesis of the noninvading strand $(F)$. Holliday junctions formed during this process $(G)$ are resolved to produce either noncrossover $(H)$ or crossover $(I)$ products. During a topoisomerase-mediated (TM) pathway (middle), migration of branchpoints and strand passages result in resolution of the intermediate $\left(G-H^{\prime}\right)$, yielding noncrossover products only. During synthesis-dependent strand annealing (SDSA) (right), as DNA synthesis proceeds through the intron, the displaced loop or bubble migrates with the replicative end $\left(E^{\prime \prime}-G^{\prime \prime}\right)$. The newly synthesized strand is released from the donor and serves as template for repair synthesis of the noninvading strand $\left(\mathrm{G}^{\prime \prime}-\mathrm{H}^{\prime \prime}\right)$ to generate noncrossover products only $\left(\mathrm{H}^{\prime \prime}\right)$. Nucleolytic activity would be required to remove any redundant sequences arising from the repair synthesis and strand annealing events. (Half-arrows) 3 ' end of DNA strands; (bold arrow) last step in each pathway. Functions implicated in homing and their putative association with appropriate steps in the homing pathways are diagrammed as follows: (solid boxes) functions directly implicated in homing (class III); (shaded boxes) functions required for replication with an assumed role in homing (class II); (open box) function not required for replication or homing (class I) but

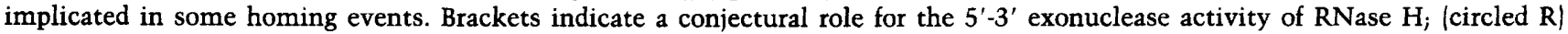
unidentified resolvases; (circled T) unidentified topoisomerases.

replicative repair (Fig. 6C,D). By inference from in vitro studies, single-stranded DNA-binding protein (gp32) binds the nucleolytically processed recipient and solicits recombinase (UvsX/UvsY) to effect strand exchange (Fig. 6C) (Yonesaki and Minagawa 1985, 1989; Kodadek 1990). Once the synaptic complex is formed, helicase activity (gp41/gp59, dda helicase) allows repair synthesis (gp1, gp43, gp44/gp62, gp45) to proceed (Fig. 6, E-G and E'$\mathrm{G}^{\prime \prime}$ ) (Formosa and Alberts 1986; Barry and Alberts 1994; Salinas and Kodadek 1995; for review, see Kruezer and Morrical 1994). Regardless of pathway, replication through the intron generates recombination intermedi- 
ates that can then be resolved by one of several independent mechanisms, as discussed below, with DNA ligase (gp30) being required to repair the nicks as a step toward generating intron-containing recombinants.

\section{Alternative pathways for intron homing}

The DSBR pathway (Figs. 1 and 6) is the mechanism that is widely assumed to account for homing (for review, see Belfort 1990; Mueller et al. 1993). Accordingly, in our model system DNA ends resulting from I-TevI cleavage invade homologous exon sequences of an intron-containing $t d$ allele and prime gap-repair synthesis. In accordance with the DSBR pathway, studies have shown that homing in phage T4 is a DSB-dependent event that requires exon homology between donor and recipient and is associated with coconversion of flanking markers (Bell-Pedersen et al. 1989; Clyman and Belfort 1992). The requirements shown here for nuclease and recombinase functions and activities required for leading-strand phage DNA synthesis (Cha and Alberts 1990) are further consistent with the DSBR pathway. However, two observations suggest that other mechanisms may also be involved in the homing event. First, intron homing in T4 can occur fairly efficiently in the absence of any known resolvase, a requisite activity for the DSBR pathway (Figs. 1 and 6; Table 1; data not shown). Second, the underrepresentation of crossover recombination products (Fig. 5) is inconsistent with DSBR as the sole pathway, in which case crossover and noncrossover products would be predicted in approximately equivalent amounts (Fig. 1). Although we have not eliminated the possibility of undiscovered resolvases, these would need to have the unprecedented property of favoring noncrossover events to account for the observed bias. The combination of these circumstances seems unlikely, implying that pathways in addition to DSBR may effect intron homing. Furthermore, results from independent coconversion studies are also consistent with multiple pathways, including but not limited to DSBR (J.E. Mueller and $M$. Belfort, in prep.; see below).

One such alternative to DSBR involves the resolution of recombination intermediates by strand passage activities of topoisomerase (Thaler et al. 1987; McGill et al. 1989; Hastings 1992). In a topoisomerase-mediated (TM) process, once the recombination intermediate is formed (Fig. 6G), the two Holliday junctions migrate toward each other, ultimately resulting in resolution (Fig. 6G$\left.\mathrm{H}^{\prime}\right)$. Although topoisomerase is required to relax the ensuing positive twist generated between the two migrating branchpoints, this pathway does not require a resolvase to effect intron mobility. Furthermore, unlike resolvase-dependent resolution of these intermediates, TM resolution results in the acquisition of all newly synthesized DNA by the recipient plasmid, and crossing over does not occur. Although a TM pathway seems like an appealing alternative to DSBR, intron homing still occurred with T4am39am 49 topoisomerase-resolvase mutants, as it did in the combined absence of T4 topoisomerase and host type II topoisomerase (gyrase) activ- ities (data not shown). Therefore, one would again need to invoke undiscovered enzymes to account for a TM pathway.

A third pathway, the synthesis-dependent strand annealing (SDSA) pathway (for review, see Haber 1992; Shinohara and Ogawa 1995), derived from the bubble migration model describing the single-stranded nature of replication products in a T4 in vitro replication system (Formosa and Alberts 1986), can account for all of the observed homing events without needing to invoke yetto-be discovered functions. This pathway has been used to explain repair of DSBs resulting from P-element transposition in Drosophila (Nassif et al. 1994). The initial steps of the SDSA pathway, involving cleavage and homologous strand invasion, are similar to those of the DSBR pathway (Fig. 6A,D). An important difference between the two mechanisms is that during SDSA initial strand displacement does not expand into a D-loop as DNA synthesis proceeds (Fig. $6 \mathrm{E}, \mathrm{F}$ ), but migrates in the $5^{\prime}-3^{\prime}$ direction likely aided by T4 helicase (gp41) and its

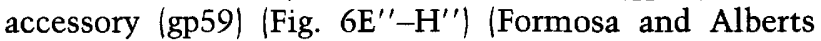
1986; Salinas and Kodadek 1995). This results in the release of a newly synthesized, single-stranded DNA molecule, which then acts as a template for complementarystrand repair, resulting in intron inheritance (Fig. 6, G', $\left.\mathrm{H}^{\prime \prime}\right)$.

The SDSA pathway is an appropriate alternative or adjunct to the DSBR pathway, as Holliday intermediates are not formed and resolvase activity is not required. Furthermore, the underrepresentation of crossover products (Fig. 5) is consistent with an SDSA mechanism as, in the absence of Holliday junctions, crossover products are not generated (Fig. $6 \mathrm{H}^{\prime \prime}$ ). In addition, unlike for the DSBR and TM pathways, no new enzymatic activities need to be invoked. Finally, results from recent coconversion studies can be reconciled by the SDSA pathway (J.E. Mueller and M. Belfort, in prep.). Although coconversion is on average bidirectional, coconversion tracks over single events are highly asymmetric, a situation that is explained readily by an asymmetric pathway such as SDSA.

The use of multiple pathways to effect DNA replication and repair is not uncommon in phage $\mathrm{T} 4$ (for review, see Mosig 1994). Likewise, our data indicate that mechanisms in addition to conventional DSBR contribute to intron homing in T4, with TM and SDSA-based pathways as likely candidates. The extent to which each pathway contributes to intron homing remains undetermined and may well rely on the replication and recombination functions available to the phage under particular growth conditions. Likewise, homing in eukaryotic systems is likely to be adapted to the particular replication, recombination, and repair pathways that are prevalent in the chloroplast, mitochondrion, or nucleus that plays host to the mobile intron.

\section{Materials and methods}

Strains and plasmids

Streptomycin-resistant $\left(\mathrm{str}^{\mathrm{R}}\right)$ derivatives of E. coli B, E. coli B 
rus-ruvA-ruvC, KLl6ruv ${ }^{+}$, and KL16ruvC-recG (Lloyd 1991) were isolated on $200 \mu \mathrm{g} / \mathrm{ml}$ of streptomycin according to Karam and $\mathrm{O}^{\prime}$ Donnell (1973). E. coli B rus-ruvA-ruvC was made by P1 transduction from strains AM821 (Arus::kan) and AM887 (Arus::kan $\Delta$ ruvAC65eda-51Tn10) provided by R. Lloyd, with selection on media containing $20 \mu \mathrm{g} / \mathrm{ml}$ of tetracycline and 50 $\mu \mathrm{g} / \mathrm{ml}$ of kanamycin. Strains were tested for sensitivity to UV irradiation and mitomycin C as described (Lloyd et al. 1974; Lloyd 1991).

Phage T4K10 (Selick et al. 1988) and variants uvsXamll, uvsY $6608,46 a m B 14,59 a m H L 628$ (described in Kreuzer et al. 1988a), and 32amA453,41amN81, 43amE4332, 44amN82, 45amE10, 61amHL627, 62amE1140 (described in Benson and Kreuzer 1992), and $49 a m E 727$ were provided by K. Kreuzer. Phage T4D was provided by D. Hall (Georgia Institute of Technology, Atlanta) and variants $1 \mathrm{amB24}, 30 \mathrm{amC104}$, 47amA456, $52 a m E 174,55 a m B L 292$, and 60amE29 were provided by L. Gold (University of Colorado, Boulder). T4D39amN116, provided by $\mathrm{K}$. Kreuzer, was used to generate T4K1039amN116 as described (Kreuzer and Miller 1994). T4alc7 (am56am42denB-rIIA) was provided by $\mathrm{H}$. Revel (University of Chicago, IL).

Plasmid pSUT4oritdAIn-r has been described (Clyman and Belfort 1992). The plasmid contains the T4 gene 34 tertiary origin at the downstream end of the HindIII-HpaI $t d$ fragment (Chu et al. 1984; Kreuzer and Alberts 1986). Plasmid pSUT4oritd $\Delta$ In-rPac was constructed by annealing oligonucleotides W469 (5'-AATTGAGATCTTAATTAAGCTT-3') and W470 (5'-CTCTGAATTAATTCGAATTAA-3') carrying the $P a c I$ restriction site (bold) and cloning the duplex into the EcoRI site of pSUT4oritd $\Delta$ In-r.

\section{Phage-to-plasmid homing assay}

Host cells containing plasmid pSUT4oritd $\Delta$ In-r were grown at $37^{\circ} \mathrm{C}$ in TBYE $(1 \%$ tryptone, $0.5 \%$ yeast extract, $0.5 \% \mathrm{NaCl})$ with streptomycin $(25 \mu \mathrm{g} / \mathrm{ml})$ and chloramphenicol $(25 \mu \mathrm{g} / \mathrm{ml})$ to an $\mathrm{OD}_{650}=0.2$. Cells were harvested by centrifugation and concentrated 10-fold to a final concentration of $2 \times 10^{9}$ cells $/ \mathrm{ml}$ in TBYE with streptomycin and chloramphenicol. Cells were infected with phage at a multiplicity of infection of 4 , diluted 10 -fold, and incubated at $37^{\circ} \mathrm{C}$ with aeration. Infection was stopped by placing cultures in a dry ice/ethanol bath. Total DNA was prepared from pelleted cells as described previously (Clyman and Belfort 1992). DNA was quantified using a Hoefer TK0-100 fluorometer as recommended by the manufacturer, digested with $S s p$ I or PacI and electrophoresed through $1 \%$ agarose in TAE ( $40 \mathrm{~mm}$ Tris-acetate, $1 \mathrm{~mm}$ EDTA). Southern blotting to Hybond-N (Amersham Corp., Arlington Heights, IL) and hybridization were performed according to Sambrook et al. (1989). The 287-bp $t d$ exon I and 734-bp $t d$ intron probes were generated by PCR using oligonucleotide primers W96 (nucleotides 294311 ) and MB21 (complementary to nucleotides 562-580) (numbering as in Chu et al. 1984), and W242 (nucleotides 901-921) and W186 (complementary to nucleotides 1613-1638) (Chu et al. 1986), respectively. The sunY probe was a $1.2-\mathrm{kb}$ SspI fragment of pMPX401 (Xu 1989). All fragments were gel-purified and labeled by random priming according to the manufacturer (GIBCO-BRL, Gaithersburg, MD). Vector probe (pSU8), lacking the $\mathrm{T} 4$ replication origin, was similarly labeled by random priming.

\section{Quantitative analysis}

Southern blots were analyzed on a Molecular Dynamics Inc. PhosphorImager using ImageQuant software, except for Figure 2 , where an autoradiogram was scanned with a Masterscan in- terpretive densitometer, using Scanalitics software. Radioactivity in each $1.9-\mathrm{kb}$ phage donor band and in each $2.2-\mathrm{kb}$ plasmid recombinant was adjusted by deducting the background value at time $=0 \mathrm{~min}$ from all time points. For individual assays, radioactivity in each band was normalized to the $1.4-\mathrm{kb}$ plasmid recipient band at time $=0 \mathrm{~min}$. This allowed a consistent analysis of data from assays performed on different variants. Similar results were obtained when either equal quantities of DNA or DNA from equal cell volumes were assayed for each time point.

\section{I-TevI activity assay}

Wild-type- and variant phage-infected cells were harvested at 30 min after infection by centrifugation and frozen in dry ice/ethanol. Pellets were resuspended in $50 \mathrm{~mm}$ Tris- $\mathrm{HCl}\langle\mathrm{pH} 7.5\rangle, 20 \%$ glucose, $400 \mu \mathrm{g} / \mathrm{ml}$ of lysozyme and subjected to two rounds of freeze/thaw. Lysates were incubated on ice for $45 \mathrm{~min}$. After centrifugation at $14,000 \mathrm{rpm}$ for $15 \mathrm{~min}$ at $4^{\circ} \mathrm{C}$, I-TevI activity was assayed with $5 \mu \mathrm{l}$ of the supernatant as described by BellPedersen et al. (1991).

\section{Endonuclease VII digestion}

SspI-digested total DNA, prepared from T4K10am49-infected recipient plasmid-containing cells, was incubated with 250 units of purified endonuclease VII (gift from B. Kemper, University of Cologne, Germany) in $50 \mathrm{~mm}$ Tris- $\mathrm{HCl}(\mathrm{pH} 8.0), 10 \mathrm{~mm}$ $\mathrm{MgCl}_{2}, 10 \mathrm{mM} \beta$-mercaptoethanol, $100 \mathrm{mg} / \mathrm{ml}$ of nuclease-free BSA for $15 \mathrm{~min}$ at $37^{\circ} \mathrm{C}$. Reactions were stopped with the addition of $1 / 4$ volume of $50 \mu \mathrm{M}$ EDTA, $5 \%$ (wt/vol) SDS, $25 \%$ (vol/vol) glycerol, $0.025 \%$ bromophenol blue.

\section{Two-dimensional gel electrophoresis}

DNA was separated by two-dimensional agarose gel electrophoresis as described by Bell and Byers (1983). Electrophoresis in the first dimension was through $0.4 \%$ agarose in $1 \times$ TAE buffer at $1.5 \mathrm{~V} / \mathrm{cm}$ for $16 \mathrm{hr}$ and in the second dimension through $1 \%$ agarose, $0.5 \mu \mathrm{g} / \mathrm{ml}$ of ethidium bromide in $1 \times$ TAE buffer at 6 $\mathrm{V} / \mathrm{cm}$ for $7 \mathrm{hr}$ at $4^{\circ} \mathrm{C}$. Gels were then blotted and hybridized as described above.

\section{Acknowledgments}

We thank M. Belisle and D. Smith for their outstanding technical assistance. We gratefully acknowledge L. Gold, D. Hall, K. Kreuzer, R.G. Lloyd, and H. Revel for providing phage and bacterial strains and B. Kemper for providing purified endonuclease VII. We thank K. Kreuzer for helpful discussion, insightful comments on the manuscript, and sharing unpublished results, and M. Bryk, L. Chapman, K. Derbyshire, V. Derbyshire, and D. Nag for their useful comments on the manuscript. We are especially thankful to Maryellen Carl for careful preparation of the manuscript. This work has been supported by grants from the National Institutes of Health (GM39422 and GM44844 to M.B., GM15454 to J.E.M., and GM13866 to J.C.).

The publication costs of this article were defrayed in part by payment of page charges. This article must therefore be hereby marked "advertisement" in accordance with 18 USC section 1734 solely to indicate this fact.

\section{References}

Barry, J. and B. Alberts. 1994. Purification and characterization of bacteriophage T4 gene 59 protein. I. Biol. Chem. 269: 33049-33062. 
Belfort, M. 1990. Phage T4 introns: Self-splicing and mobility. Annu. Rev. Genet. 24: 363-385.

Belfort, M. and P.S. Perlman. 1995. Mechanisms of intron mobility. J. Biol. Chem. 270: 30237-30240.

Bell, L. and B. Byers. 1983. Separation of branched from linear DNA by two-dimensional gel electrophoresis. Anal. Biochem. 130: 527-535.

Bell-Pedersen, D., S.M. Quirk, M. Aubrey, and M. Belfort. 1989. A site-specific endonuclease and co-conversion of flanking exons associated with the mobile $t d$ intron of phage $\mathrm{T} 4$. Gene 82: 119-126.

Bell-Pedersen, D., S. Quirk, J. Clyman, and M. Belfort. 1990. Intron mobility in phage $\mathrm{T} 4$ is dependent upon a distinctive class of endonucleases and independent of DNA sequences encoding the intron core: Mechanistic and evolutionary implications. Nucleic Acids Res. 18: 3763-3770.

Bell-Pedersen, D., S.M. Quirk, M. Bryk, and M. Belfort. 1991. I-TevI, the endonuclease encoded by the mobile $t d$ intron, recognizes binding and cleavage domains on its DNA target. Proc. Natl. Acad. Sci. 88: 7719-7723.

Benson, K.H. and K.N. Kreuzer. 1992. Plasmid models for bacteriophage T4 DNA replication: Requirements for fork proteins. J. Virol. 66: 6960-6968.

Cha, T.-A. and B.M. Alberts. 1990. Effects of the bacteriophage T4 gene 41 and gene 32 proteins on RNA primer synthesis: Coupling of leading- and lagging-strand DNA synthesis at a replication fork. Biochemistry 29: 1791-1798.

Christensen, A.C. and E.T. Young. 1983. Characterization of T4 transcripts. In Bacteriophage T4 (ed. C.K. Mathews, E.M. Kutter, G. Mosig, and P. Berget), pp. 3574-3578. ASM Press, Washington, DC.

Chu, F.K., G.F. Maley, F. Maley, and M. Belfort. 1984. Intervening sequence in the thymidylate synthase gene of bacteriophage T4. Proc. Natl. Acad. Sci. 81: 3049-3053.

Chu, F.K., G.F. Maley, D.K. West, M. Belfort, and F. Maley. 1986. Characterization of the intron in the phage T4 thymidylate synthase gene and evidence for its self-excision from the primary transcript. Cell 45: 157-166.

Chu, F.K., G. Maley, J. Pedersen-Lane, A.-M. Wang, and F. Maley. 1990. Characterization of the restriction site of a prokaryotic intron-encoded endonuclease. Proc. Natl. Acad. Sci. 87: 3574-3578.

Clyman, J. and M. Belfort. 1992. Trans and cis requirements for intron mobility in a prokaryotic system. Genes \& Dev. 6: $1269-1279$.

Cunningham, R.P. and H. Berger. 1977. Mutations affecting genetic recombination in bacteriophage T4D. Virology 80: 6782.

1978. Mutations affecting genetic recombination in bacteriophage T4D. II. Genetic properties. Virology 88: 62-70.

Epstein, R.H., A. Bolle, C.M. Steinberg, E. Kellenberger, E. Boy De La Tour, R. Chevalley, R.S. Edgar, M. Susman, G.H. Denhardt, and A. Leilausis. 1964. Physiological studies of conditional lethal mutants of bacteriophage T4D. Cold Spring Harbor Symp. Quant. Biol. 28: 375-392.

Formosa, T. and B.M. Alberts. 1986. DNA synthesis dependent on genetic recombination: Characterization of a reaction catalyzed by purified bacteriophage $\mathrm{T} 4$ proteins. Cell 47: 793-806.

Gott, J.M., A. Zeeh, D. Bell-Pedersen, K. Ehrenman, M. Belfort, and D.A. Shub. 1988. Genes within genes: Independent expression of phage $\mathrm{T} 4$ intron open reading frames and the genes in which they reside. Genes \& Dev. 2: 1791-1799.

Haber, J.H. 1992. Mating-type gene switching in Saccharomyces cerevisiae. Trends Genet. 8: 446-452.

Hastings, P.J. 1992. Mechanism and control of recombination in fungi. Mutat. Res. 284: 97-110.

Hollingsworth, H.C. and N.G. Nossal. 1991. Bacteriophage T4 encodes an RNase $\mathrm{H}$ which removes RNA primers made by the T4 DNA replication system in vitro. I. Biol. Chem. 266: 1888-1897.

Karam, J.D. and P.V. O'Donnell. 1973. Suppression of amber mutations of bacteriophage T4 gene 43 (DNA polymerase) by translational ambiguity. J. Virol. 11: 933-945.

Kemper, B. and D.T. Brown. 1976. Function of gene 49 of bacteriophage T4. II. Analysis of intracellular development and the structure of very fast-sedimenting DNA. I. Virol. 18: 1000-1015.

Kodadek, T. 1990. The role of the bacteriophage T4 gene 32 protein in homologous pairing. J. Biol. Chem. 265: 2096620969.

Kreuzer, K.N. and B.M. Alberts. 1986. Characterization of a defective phage system for the analysis of bacteriophage T4 DNA replication origins. J. Mol. Biol. 188: 185-198.

Kreuzer, H.E. and E.S. Miller. 1994. Rapid screening of phage progeny from multiple factor crosses. In Molecular biology of bacteriophage T4 (ed. J.D. Karam), pp. 442-443. ASM Press, Washington, DC.

Kreuzer, K.N. and S.W. Morrical. 1994. Initiation of DNA replication. In Molecular biology of bacteriophage T4 (ed. J.D. Karam), pp. 28-42. ASM Press, Washington, DC.

Kreuzer, K.N., H.W. Engman, and W.Y. Yap. 1988a. Tertiary initiation of replication in bacteriophage T4. J. Biol. Chem. 263: 11348-11357.

Kreuzer, K.N., W.Y. Yap, A.E. Menkens, and H.W. Engman. 1988b. Recombination-dependent replication of plasmids during bacteriophage $\mathrm{T} 4$ infection. $J$. Biol. Chem. 263: 11366-11373.

Kreuzer, K.N., M. Saunders, L.J. Weislo, and H.W.E. Kreuzer. 1995. Recombination-dependent DNA replication stimulated by double-strand breaks in bacteriophage T4. J. Bacteriol. 177: 6844-6853.

Lambowitz, A.M. 1989. Infectious introns. Cell 56: 323-326.

Lambowitz, A.M. and M. Belfort. 1993. Introns as mobile genetic elements. Annu. Rev. Biochem. 62: 587-622.

Leung, D., M.T. Behme, and K. Ebisuzaki. 1975. Effect of DNA delay mutations of bacteriophage $\mathrm{T} 4$ on genetic recombination. J. Virol. 16: 203-205.

Liu, L.F., C.-C. Liu, and B.M. Alberts. 1979. T4 DNA topoisomerase: A new ATP-dependent enzyme essential for initiation of T4 bacteriophage DNA replication. Nature 281: 456-461.

Lloyd, R.G. 1991. Conjugational recombination in resolvasedeficient ruvC mutants of Escherichia coli $\mathrm{K}-12$ depends on recG. I. Bacteriol. 173: 5414-5418.

Lloyd, R.G. and G.J. Sharples. 1993. Dissociation of synthetic Holliday junctions by $E$. coli RecG protein. EMBO J. 12: 1722.

Lloyd, R.G., B. Low, G.N. Godson, and E.A. Birge. 1974. Isolation and characterization of an Escherichia coli K-12 mutant with a temperature-sensitive RecA- phenotype. J. Bacteriol. 120: $407-415$.

McCarthy, D. 1979. Gyrase-dependent initiation of bacteriophage T4 DNA replication: Interaction of Escherichia coli gyrase with novobiocin, coumermycin and phage DNA-delay gene products. $J$. Mol. Biol. 127: 265-283.

McGill, C., B. Shafer, and J. Strathern. 1989. Coconversion of flanking sequences with homothallic switching. Cell 57: 459-467.

Mickelson, C. and J.S. Wiberg. 1981. Membrane-associated DNase activity controlled by genes 46 and 47 of bacteriophage T4D and elevated DNase activity associated with the 


\section{Mueller et al.}

T4 das mutation. I. Virol. 40: 65-77.

Mizuuchi, K., B. Kemper, J. Hays, and R.A. Weisberg. 1982. T4 endonuclease VII cleaves Holliday structures. Cell 29: 357365.

Mosig, G. 1994. Homologous recombination. In Molecular biology of bacteriophage T4 (ed. J.D. Karam), pp. 54-82. ASM Press, Washington, DC.

Mosig, G., A. Luder, A. Ernst, and N. Canan. 1991. Bypass of a primase requirement for bacteriophage T4 DNA replication in vivo by a recombination enzyme, endonuclease VII. New Biol. 3: 1195-1205.

Mueller, J.E., M. Bryk, N. Loizos, and M. Belfort. 1993. Homing endonucleases. In Nucleases, 2nd ed. (ed. S.M. Linn, R.S. Lloyd, and R.J. Roberts), pp. 111-143. Cold Spring Harbor Laboratory Press, Cold Spring Harbor, NY.

Nassif, N., J. Penney, S. Pal, W.R. Engels, and G.B. Gloor. 1994. Efficient copying of nonhomologous sequences from ectopic sites via P-element-induced gap repair. Mol. Cell. Biol. 14: $1613-1625$.

Nossal, N.G. and D.M. Hinton. 1987. Bacteriophage T4 DNA primase-helicase: Characterization of the DNA synthesis primed by $\mathrm{T} 461$ protein in the absence of $\mathrm{T} 441$ protein. $I$. Biol. Chem. 254: 10879-10885.

Orr-Weaver, T.L., J.W. Szostak, and R.J. Rothstein. 1981. Yeast transformation: A model system for the study of recombination. Proc. Natl. Acad. Sci. 78: 6354-6358.

Perlman, P.S. and R.A. Butow. 1989. Mobile introns and intronencoded proteins. Science 246: 1106-1109.

Quirk, S.M., D. Bell-Pedersen, and M. Belfort. 1989. Intron mobility in the T-Even phages: High frequency inheritance of group I introns promoted by intron open reading frames. Cell 56: $455-465$.

Salinas, F. and T. Kodadek. 1995. Phage T4 homologous strand exchange: A DNA helicase, not the strand transferase, drives polar branch migration. Cell 82: 111-119.

Sambrook, J., E.F. Fritsch, and T. Maniatis. 1989. Molecular cloning: A laboratory manual. Cold Spring Harbor Laboratory Press, Cold Spring Harbor, NY.

Selick, H.E., K.N. Kreuzer, and B.M. Alberts. 1988. The bacteriophage T4 insertion/substitution vector system. A method for introducing site-specific mutations into the virus chromosome. J. Biol. Chem. 263: 11336-11347.

Sharples, G.J., S.N. Chan, A.A. Mahdi, M.C. Whitby, and R.G. Lloyd. 1994. Processing of intermediates in recombination and DNA repair: Identification of new endonuclease that specifically cleaves Holliday junctions. EMBO I. 13: 61336142.

Shinohara, A. and T. Ogawa. 1995. Homologous recombination and the roles of double-strand breaks. Trends Biochem. Sci. 20: 387-391.

Stetler, G.L., G.J. King, and W.M. Huang. 1979. T4 DNA-delay proteins, required for specific DNA replication, form a complex that has ATP-dependent DNA topoisomerase activity. Proc. Natl. Acad. Sci. 76: 3737-3741.

Szostak, J.W., T.L. Orr-Weaver, R.J. Rothstein, and F.W. Stahl. 1983. The double-strand-break repair model for recombination. Cell 33: 25-35.

Thaler, D.S., M.M. Stahl, and F.W. Stahl. 1987. Tests of the double-strand-break repair model for red-mediated recombination of phage lambda and plasmid lambda $\mathrm{dv}$. Genetics 116: $501-511$.

West, D.K., M. Belfort, G.F. Maley, and F. Maley. 1986. Cloning and expression of an intron-deleted phage T4 $t d$ gene. J. Biol. Chem. 261: 13446-13450.

Xu, M. 1989. "Characterization of a new self-splicing group I intron in bacteriophage T4." Ph.D. thesis, State University of New York, Albany, NY.

Yonesaki, T. 1994. Involvement of a replicative DNA helicase of bacteriophage T4 in DNA recombination. Genetics 138: $247-252$.

Yonesaki, T. and T. Minagawa. 1985. T4 phage gene uvs $X$ product catalyzes homologous DNA pairing. EMBO J. 4: 33213327.

1989. Synergistic action of three recombination gene products of bacteriophage T4, uvsX, uvsY, and gene 32 proteins. J. Biol. Chem. 264: 7814-7820. 


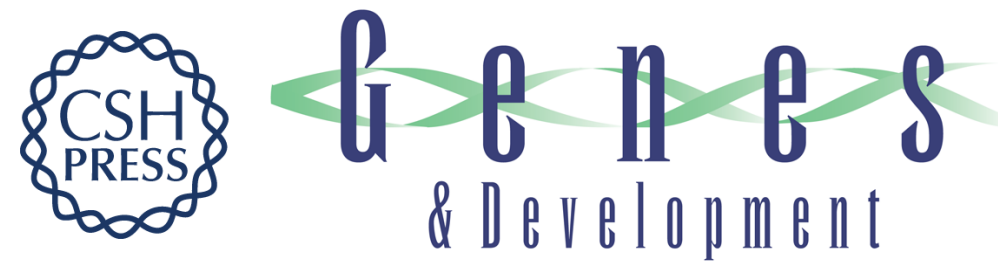

\section{Intron mobility in phage T4 occurs in the context of recombination-dependent DNA replication by way of multiple pathways.}

J E Mueller, J Clyman, Y J Huang, et al.

Genes Dev. 1996, 10:

Access the most recent version at doi:10.1101/gad.10.3.351

References This article cites 56 articles, 28 of which can be accessed free at: http://genesdev.cshlp.org/content/10/3/351.full.html\#ref-list-1

License

Email Alerting Service

Receive free email alerts when new articles cite this article - sign up in the box at the top right corner of the article or click here.

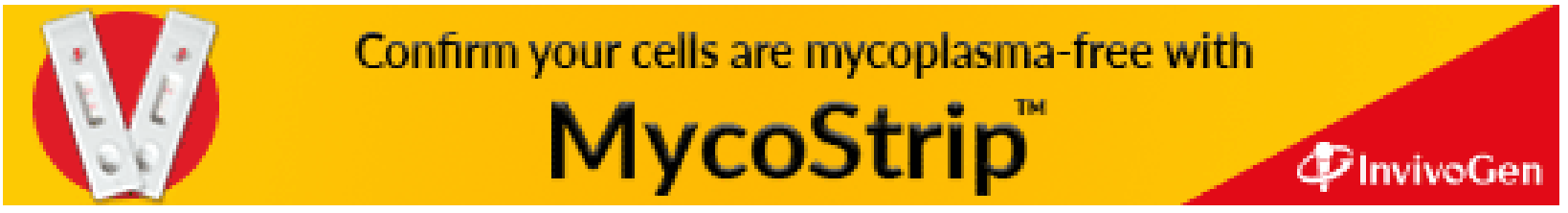

